Article

\title{
Disproportionate Effect of Sub-Micron Topography on Osteoconductive Capability of Titanium
}

\author{
Juri Saruta ${ }^{*}+{ }^{+}$, Nobuaki Sato ${ }^{\dagger}$, Manabu Ishijima, Takahisa Okubo, Makoto Hirota and \\ Takahiro Ogawa \\ Weintraub Center for Reconstructive Biotechnology, Division of Advanced Prosthodontics, UCLA School of \\ Dentistry, Los Angeles, CA 90095-1668, USA \\ * Correspondence: saruta@kdu.ac.jp; Tel./Fax: +81-46-822-9537 \\ + These authors contributed equally to this work.
}

Received: 2 July 2019; Accepted: 17 August 2019; Published: 18 August 2019

\begin{abstract}
Titanium micro-scale topography offers excellent osteoconductivity and bone-implant integration. However, the biological effects of sub-micron topography are unknown. We compared osteoblastic phenotypes and in vivo bone and implant integration abilities between titanium surfaces with micro- $(1-5 \mu \mathrm{m})$ and sub-micro-scale $(0.1-0.5 \mu \mathrm{m})$ compartmental structures and machined titanium. The calculated average roughness was $12.5 \pm 0.65,123 \pm 6.15$, and $24 \pm 1.2 \mathrm{~nm}$ for machined, micro-rough, and sub-micro-rough surfaces, respectively. In culture studies using bone marrow-derived osteoblasts, the micro-rough surface showed the lowest proliferation and fewest cells attaching during the initial stage. Calcium deposition and expression of osteoblastic genes were highest on the sub-micro-rough surface. The bone-implant integration in the Sprague-Dawley male rat femur model was the strongest on the micro-rough surface. Thus, the biological effects of titanium surfaces are not necessarily proportional to the degree of roughness in osteoblastic cultures or in vivo. Sub-micro-rough titanium ameliorates the disadvantage of micro-rough titanium by restoring cell attachment and proliferation. However, bone integration and the ability to retain cells are compromised due to its lower interfacial mechanical locking. This is the first report on sub-micron topography on a titanium surface promoting osteoblast function with minimal osseointegration.
\end{abstract}

Keywords: acid-etching; micro-rough; bone regeneration; sub-micro-rough; bone integration; osseointegration; dental implants; orthopedic implants

\section{Introduction}

Titanium and titanium alloy have been widely used in the fields of orthopedic surgery and dentistry owing to their excellent mechanical properties, high corrosion resistance, and suitable biocompatibility [1-3]. Uses include endosseous implants and various bone regenerative devices, such as pins and screws to immobilize bone and plates and scaffolds to guide bone generation [1,4-8]. To improve the biocompatibility of titanium, particularly its osteoconductivity, various methods of surface modification have been developed to roughen titanium surfaces. Surface modifications consist of mechanical, chemical, and physicochemical treatments, as well as other coating-based methods, including machining, sand-blasting, acid-etching, anodization, plasma spraying, laser treatment, apatite-coating, or a combination of these $[9,10]$.

Surface topography and roughness influence the biological responses of osteoblast cells [11]. For improved osseointegration of implants, researchers have assessed the impact of surface roughness at the micro-scale [12]. Surface roughness not only increases the surface area but also triggers biological changes, such as the skeletal and morphological alteration of cells. These changes can affect planar cell polarity, as well as gene expression and the differentiation and maturation of 
osteoblasts $[13,14]$. In the past, studies have reported that, even in the absence of additional osteogenic factors, micro-textured titanium surfaces can promote the differentiation and maturation of osteoblasts and implant osseointegration better than relatively smoother surfaces, such as machined surfaces $[15,16]$. In fact, bone formation occurs in structurally complex areas generated through the process of bone deposition and resorption by osteoblasts and osteoclasts [12,14], and these areas present micro-scale roughness features. Titanium surfaces with various micro-scale topographies developed to date have been shown to provide osteoblasts with structural mimetics and thereby biological cues to promote new bone formation [17].

Presently, a micro-rough titanium surface created by acid-etching is one of the most commonly used surfaces in endosseous implants. This particular surface is characterized by a compartmental structure consisting of pits and peaks, ranging in size from 1 to $5 \mu \mathrm{m}$ [18]. Sulfuric acid $\left(\mathrm{H}_{2} \mathrm{SO}_{4}\right)$ is used in this surface modification, although many other strong acids, such as hydrochloric acid $(\mathrm{HCl})$, nitric acid $\left(\mathrm{HNO}_{3}\right)$, and hydrogen fluoride $(\mathrm{HF})$, have been tested [1,19]. The acid-etched micro-rough titanium surface promotes osteoblastic differentiation, and thereby bone formation around it, better than smoother surfaces, such as a machined surface $[1,20]$. The improved osteoconductivity provides the therapeutic benefits of faster bone formation and, more importantly, a stronger anchorage of implants into bone, referred to as bone-implant integration or osseointegration. However, sub-micron topographies have rarely been developed or applied to titanium implants, and their biological impacts are largely unknown.

We have created a new titanium surface with sub-micro-topography. The purpose of this study was to examine the rate of osteoblastic differentiation on this new surface as well as its interfacial locking ability at the cellular and tissue levels.

\section{Results}

\subsection{Surface Morphology of Titanium}

Macroscopically, the machined surface was light gray with a metallic luster (Figure 1a,d), whereas the micro-rough surface was dark gray with no metallic luster (Figure 1b,e). The sub-micro-rough surface was grayish, similar to the machined surface, but with less metallic luster (Figure 1c,f).

Low-magnification scanning electron microscopy (SEM) images of the machined surface showed parallel traces formed during the concentric machining process (Figure 1g,j). High-magnification images of the machined surface showed undefined irregularities (Figure $1 \mathrm{~m}$ ). The micro-rough surface showed a typical micro-roughened morphology, consisting of microscale pits with $1-5 \mu \mathrm{m}$ in peak-to-peak distance (approximately $1.5 \mu \mathrm{m}$ on average) (Figure 1h,k,n). Low-magnification images of the sub-micro-rough surface showed no recognizable roughness with faintly machine traces (Figure 1i). Higher magnification images of the sub-micro-rough surface showed roughness consisting of pits smaller than those on the micro-rough surface (Figure $11, \mathrm{o}$ ). The pits were $0.1-0.5 \mu \mathrm{m}$, with an average size of $0.15 \mu \mathrm{m}$ (Figure 1o). 
Machined

a

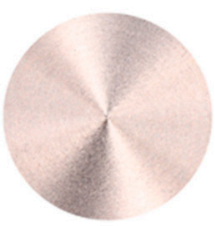

d
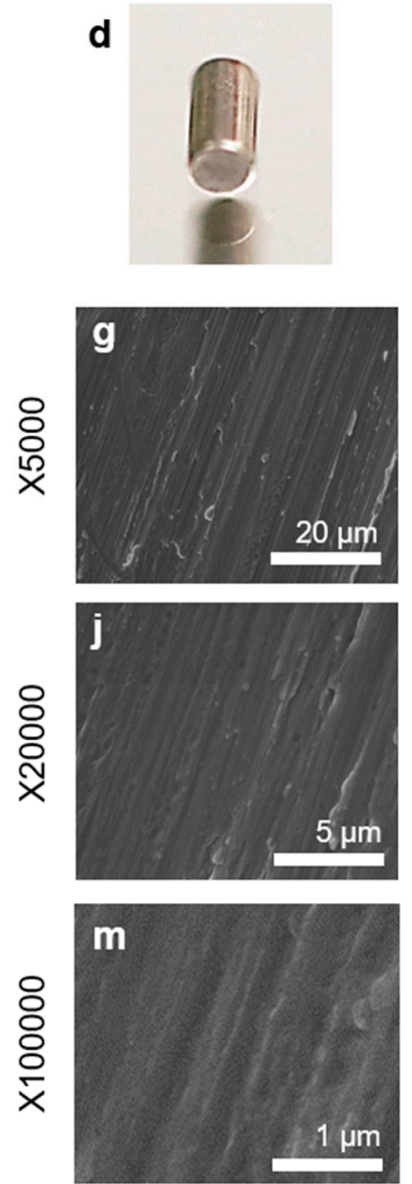

Micro-rough

b

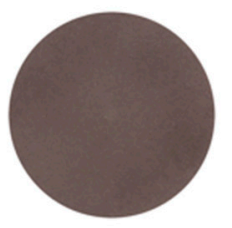

e
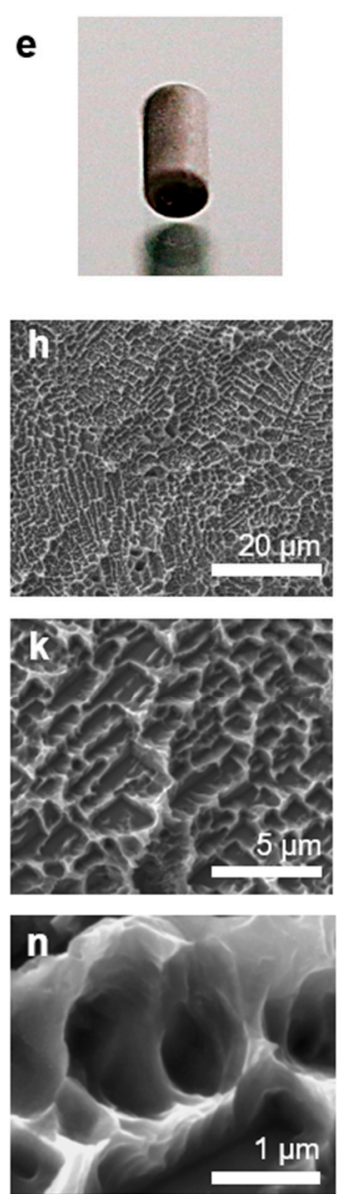

Sub-micro-rough

C

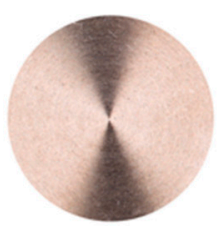

f
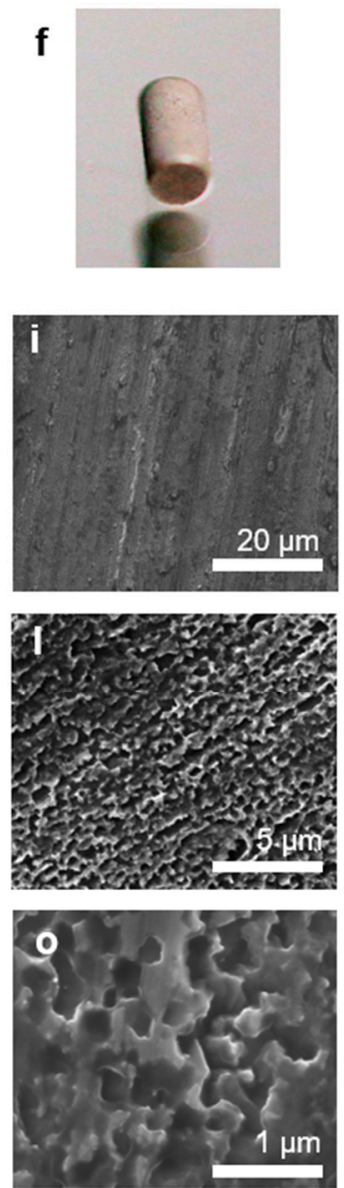

Figure 1. Surface morphology of the titanium disks and implants used in this study. (a,d) Macroscopic findings of the smooth surface. (b,e) Macroscopic findings of the micro-rough surface. (c,f) Macroscopic findings of the sub-micro-rough surface. Scanning electron microscopy photographs showing the surface roughness of the smooth $(\mathbf{g}, \mathbf{j}, \mathbf{m})$, micro-rough $(\mathbf{h}, \mathbf{k}, \mathbf{n})$, and sub-micro-rough $(\mathbf{i}, \mathbf{l}, \mathbf{o})$ surfaces at magnifications of $5000 \times(\mathbf{g}, \mathbf{h}, \mathbf{i}), 20,000 \times(\mathbf{j}, \mathbf{k}, \mathbf{l})$, and 100,000× $(\mathbf{m}, \mathbf{n}, \mathbf{o})$. Scale bars $=(\mathbf{g}, \mathbf{h}, \mathbf{i}) 20 \mu \mathrm{m}$, $(\mathbf{j}, \mathbf{k}, \mathbf{l}) 5 \mu \mathrm{m}$, and $(\mathbf{m}, \mathbf{n}, \mathbf{o}) 1 \mu \mathrm{m}$.

\subsection{Quantitative Topographical Evaluations of Titanium Surfaces}

To identify potential measurable differences in surface morphology among the three surfaces, quantitative assessments of 3-dimensional profiles were performed. The results showed that roughness parameters such as average roughness and mean peak-to-valley height were significantly greater on the sub-micro-rough surface than on the machined surface and significantly greater on the micro-rough surface than on the sub-micro-rough surface (Figure 2a,b). The average width of roughness profile elements was significantly higher on both the machined and micro-rough surfaces than on the sub-micro-rough surface, whereas there was no significant difference between the machined and micro-rough surfaces (Figure 2c). The skewness of the roughness profile was highest on the micro-rough surface and lowest on the sub-micro-rough surface (Figure 2d). 

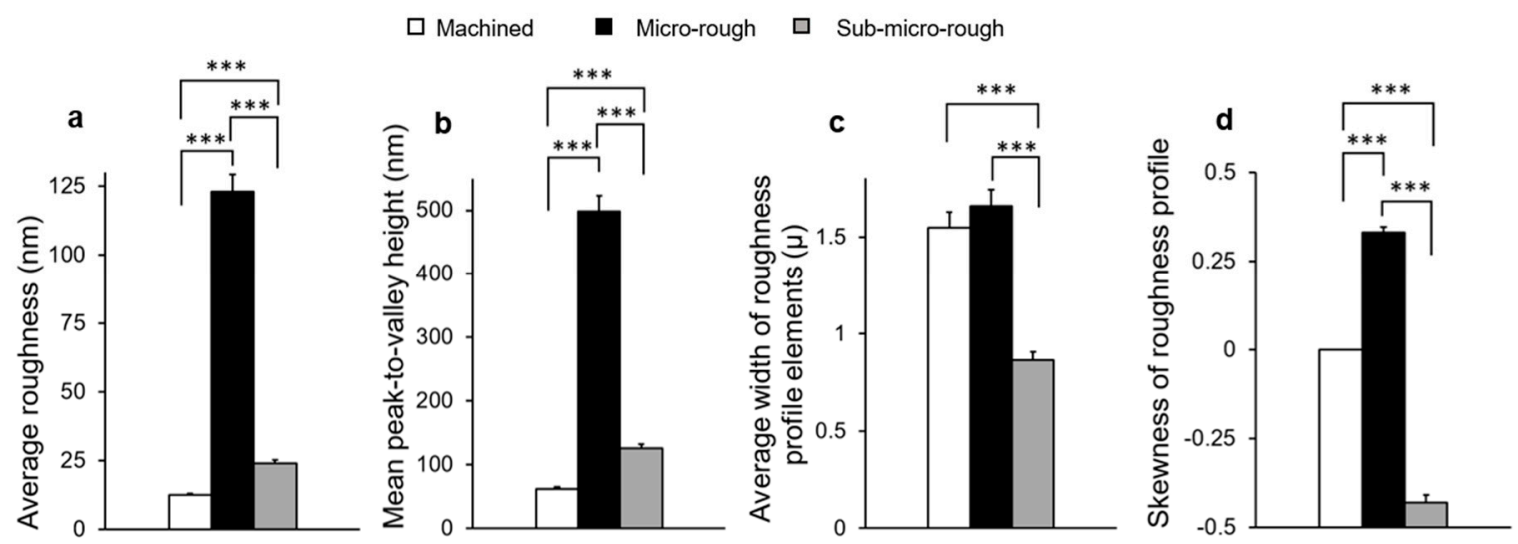

Figure 2. Quantitative measurements of surface roughness of the machined, micro-rough, and sub-micro-rough surfaces using a 3-dimensional profiler. (a) Average roughness, (b) mean peak-to-valley height, (c) average width of roughness profile elements, and (d) skewness of roughness profile. Each value represents the mean \pm standard deviation of six sites on the three different surfaces $(n=6)$. *** $p<0.001$, one-way ANOVA followed by Tukey's test.

\subsection{Cell Attachment, Proliferation, and Functional Phenotypes}

The effect of cell attachment onto titanium surfaces was assessed based on the numbers of cells attached to the titanium surfaces after a $24 \mathrm{~h}$ culture period. The number of osteoblasts attached to each titanium disk was evaluated after $24 \mathrm{~h}$ of incubation using a WST-1-based colorimetric assay (Figure 3a). After $24 \mathrm{~h}$ of seeding, significantly more cells were attached to the machined and sub-micro-rough surfaces than the micro-rough surface. The number of attached cells was 2.8 times higher for the machined surface and 2.4 times higher for sub-micro-rough surface than for the micro-rough surface (Figure 3a).

The number of propagated cells on each titanium surface was assessed based on the cell density on the titanium surfaces on day 3 of the culture period. Cell density, as measured on day 3, was significantly greater on the machined surface than on the micro-rough or sub-micro-rough surfaces and was significantly greater on the sub-micro-rough surface than on the micro-rough surface. The cell density was 5.3 times greater for the machined surface and 2.1 times greater for the sub-micro-rough surface than for the micro-rough surface (Figure 3b).

To assess osteoblastic phenotypes on titanium surfaces, bone-related gene analysis was performed using quantitative PCR at two time points. At day 7 of culture, quantitative PCR showed that the expression of collagen type I alpha 1 chain (Col1a1), an early marker of osteoblastic differentiation, was significantly greater on the micro-rough surface than on the machined surface, and greater still on the sub-micro-rough surface. Expression was upregulated 1.4- and 3.1-fold on the micro-rough and sub-micro-rough surface, respectively, compared to that on the machined surface. At day 14 of culture, the trends seen on day 7 persisted, with the sub-micro-rough surface showing the highest expression of Col1a1 and the machined surface showing the lowest (Figure 3c).

At day 7 of culture, the expression of osteopontin (Opn), a mid- to late-stage osteoblastic marker, was upregulated on the micro-rough and sub-micro-rough surfaces. In particular, marked upregulation was observed on the sub-micro-rough surface. At day 14 of culture, there was also a significant increase in Opn expression on both micro-rough and sub-micro-rough surfaces compared to levels on the machined surface, although there was no significant difference between the micro-rough and sub-micro-rough surfaces (Figure 3d).

The level of calcium deposition was evaluated as a later-stage osteoblastic phenotype. Total calcium deposition on day 14 was significantly greater on the micro-rough surface than on the machined surface and was greater still on the sub-micro-rough surface (Figure 3e, bottom). The 
Alizarin red-positive area was largest on the sub-micro-rough surface and smallest on the machined surface, confirming the calcium deposition results (Figure 3e, top).
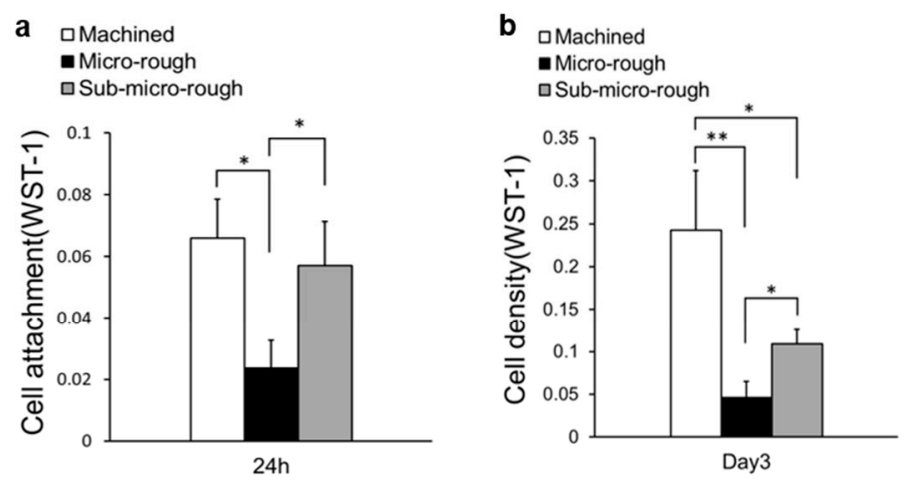

C Machined aSub-micro-rough

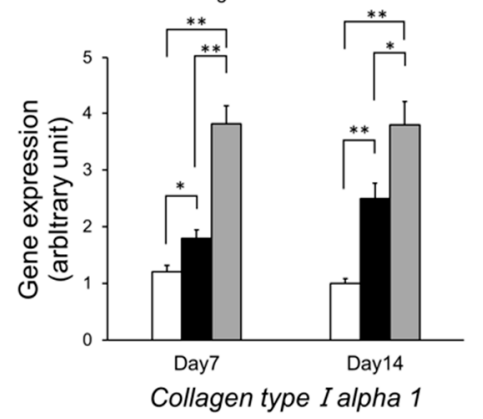

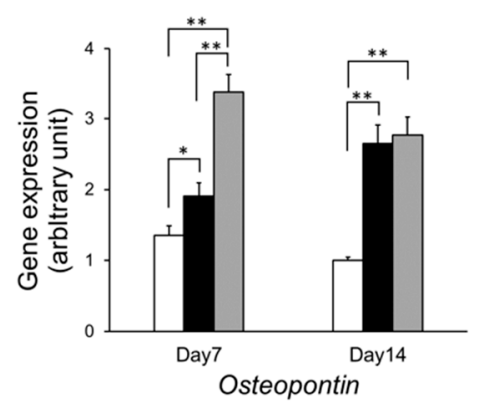

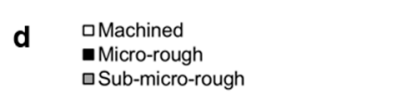

e

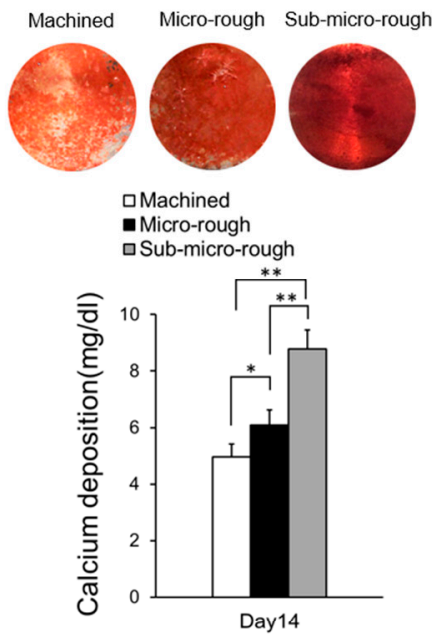

Figure 3. Biological characteristics of osteoblasts on three different titanium surfaces. (a) Number of cells attached to each titanium surface during a $24 \mathrm{~h}$ incubation, evaluated by a WST- 1 assay. (b) Cell density evaluated at culture day 3 using a WST-1 assay. (c,d) Real-time qPCR analysis of mRNA expression of bone-related genes collagen type I alpha 1 and osteopontin on titanium surfaces at day 7 and day 14 using osteoblastic cell cultures. Relative expression levels ( $2^{-\Delta \Delta C t}$ values) of the genes of interest were normalized to that of the housekeeping gene Gapdh. (e) Representative images of mineral deposition evaluated by Alizarin red staining at culture day 14 (top). Colorimetric detection of total calcium deposition measured on the same day (bottom). Each value represents the mean \pm standard deviation of triplicate experiments $(n=3) .{ }^{*} p<0.05,{ }^{* *} p<0.01$, one-way ANOVA followed by Tukey's test.

\subsection{Detachment of Osteoblasts from Different Titanium Surfaces}

The detachment test was performed to determine the cell-titanium surface attachment strength in vitro. The detachment test performed on culture day 3 showed that approximately $80 \%$ of cells detached from the machined and sub-micro-rough surfaces, whereas only $25 \%$ of cells detached from the micro-rough surface (Figure 4a). There was no significant difference between the machined and sub-micro-rough surfaces. Detachment tests on days 7 and 14 showed a similar trend to that on day 3 . The percentage of detached cells was significantly reduced on the micro-rough surface but not on the sub-micro-rough surface compared to that on the machined surface (Figure 4a).

SEM qualitative observation was performed to confirm the results of the detachment tests. On day 3, most cells had detached from the machined and sub-micro-rough surfaces, whereas a higher percentage of cells remained present on the micro-rough surface (Figure $4 \mathrm{~b}-\mathrm{g}$ ). On day 14 , a greater number of cells were present on titanium disks than on day 3. A majority of the cells detached from the machined and sub-micro-rough surfaces after the detachment test, whereas a significant number of cells remained adhered to the micro-rough surface (Figure $4 \mathrm{~h}-\mathrm{m}$ ). 
a
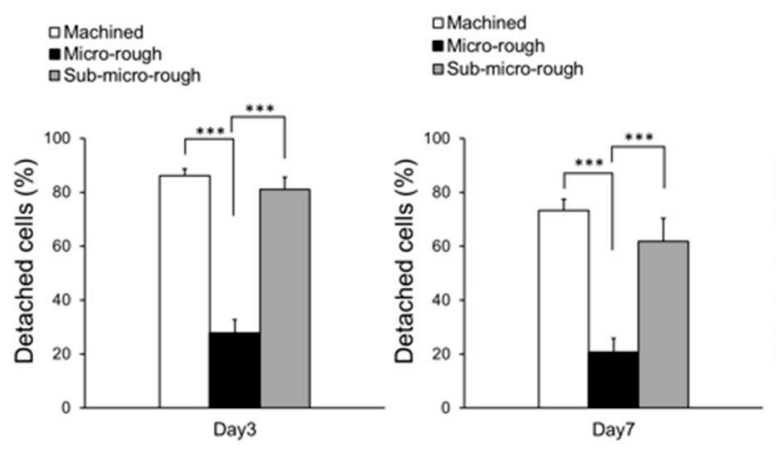

aMachined
Micro-rough

Micro-rough

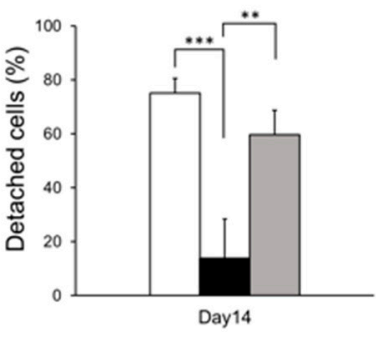

Machined
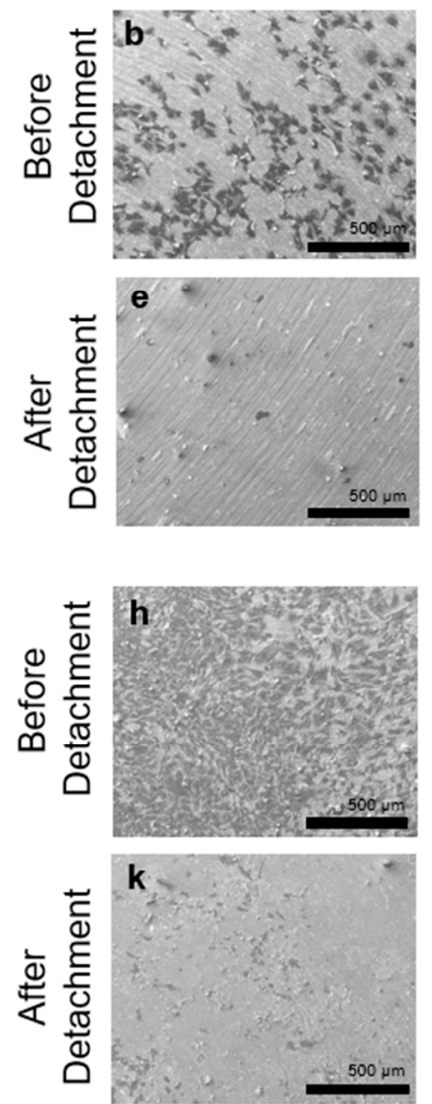

Micro-rough
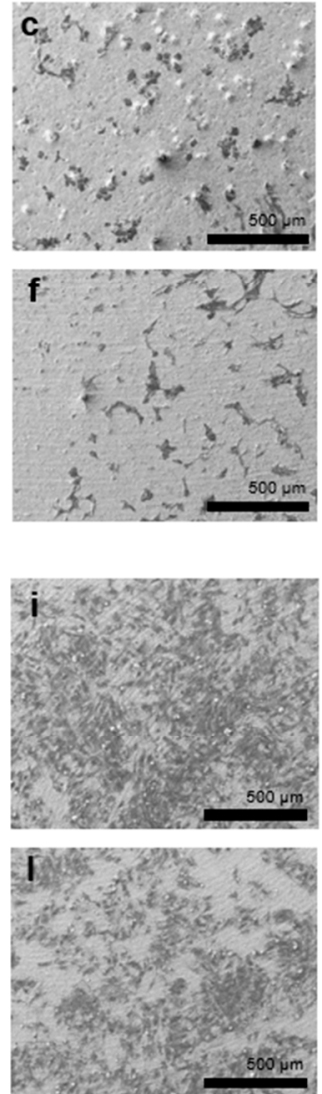

\section{Sub-micro-rough}
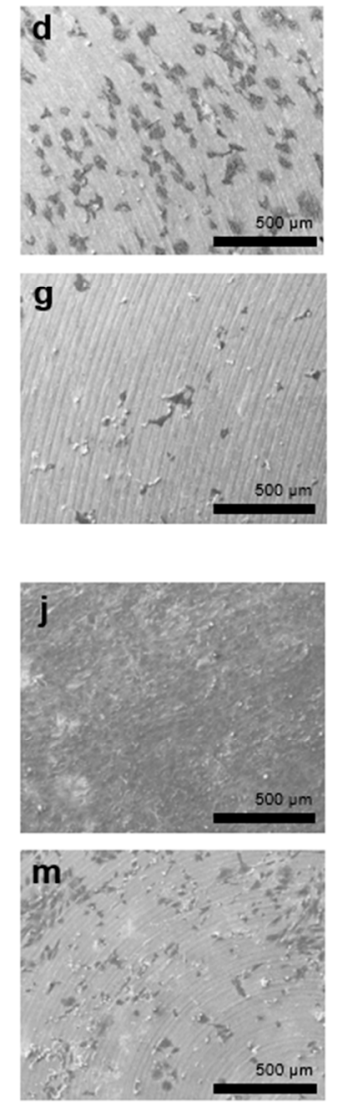

Figure 4. Results of detachment assay on three different titanium surfaces. (a) The percentage of detached osteoblasts from three different titanium surfaces after incubation for 3, 7, and 14 days. Each value represents the mean \pm standard deviation of triplicate experiments $(n=3) .{ }^{* *} p<0.01$, *** $p<0.001$, one-way ANOVA followed by Tukey's test. (b-d) Representative scanning electron microscopy (SEM) photographs of osteoblasts before detachment from three different titanium surfaces on day 3 of culture. (e-g) Representative SEM photographs of osteoblasts after detachment from three different titanium surfaces on day 3 of culture. (h-j) Representative SEM photographs of osteoblasts before detachment from three different titanium surfaces on day 14 of culture. (k-m) Representative SEM photographs of osteoblasts after detachment from three different titanium surfaces on day 14 of culture. Scale bar $=500 \mu \mathrm{m}$. 


\subsection{Biomechanical Strength of Bone and Titanium Integration}

A push-in value that directly represents the shear strength of integration between the bone and implant was used to evaluate the osseointegration. The in vivo strength of bone-implant integration as evaluated by the push-in test was 5.5 times higher for the micro-rough surface than for the machined surface. The sub-micro-rough surface did not show a significant increase compared to the value of the machined surface (Figure 5). The strength of bone-implant integration for the sub-micro-rough surface was significantly lower than that for the micro-rough surface.

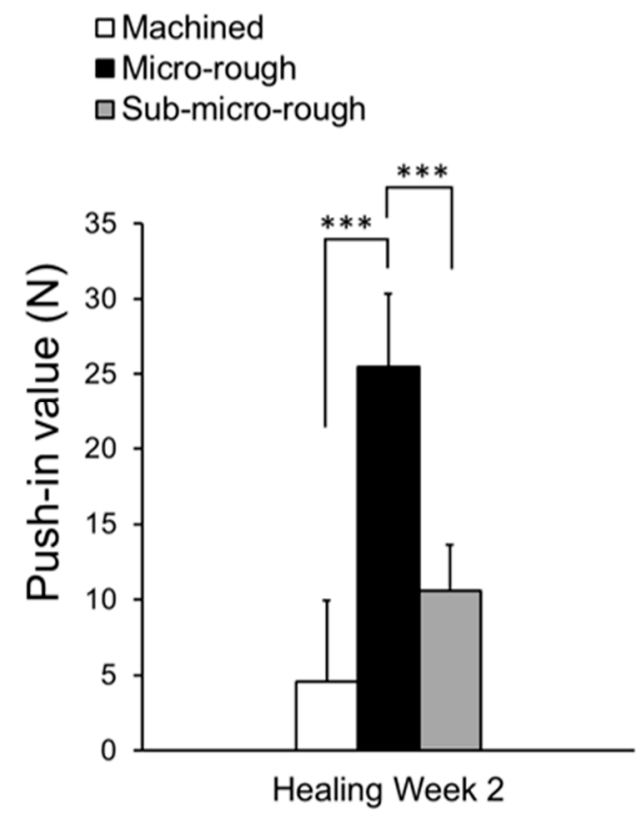

Figure 5. The strength of implant anchorage in bone, evaluated by the biomechanical push-in test in a rat femur model. Each bar represents mean \pm standard deviation of machined $(n=5)$, micro-rough $(n=5)$, or sub-micro-rough $(n=5)$ titanium. ${ }^{* *} p<0.001$, one-way ANOVA followed by Tukey's test.

\section{Discussion}

In this study, we aimed to evaluate the osteoconductivity and anchorage capability of a sub-micro-rough titanium surface as compared to machined and micro-rough surfaces. All in vitro results indicated that the sub-micro-rough surface promoted osteoblastic differentiation even more than the micro-rough surface. Interestingly, this enhanced osteoblastic differentiation did not result in an increase in in vivo bone and implant integration, probably due to the limited mechanical retention of bone tissue. Performance of the detachment assay on cultured osteoblasts revealed that the ability to retain cells was substantially reduced on the sub-micro-rough surface compared with that of the micro-rough surface. Despite the effective surface roughening provided by the low-temperature acid-etching, the cell retention ability remained similar to that of the machined surface. Together, our results indicate that the sub-micro-rough surface exhibits new surface features that effectively promote osteoblastic differentiation but not the mechanical interfacial engagement of cells and bone tissue. The fact that the surface roughness has disproportionate effects on osteoconductivity on the one hand and on bone and titanium integration on the other represents a significant finding.

Although the effect of nano-features on titanium surfaces has been studied, little information was available on the effect of sub-micro-features. We developed a new method for creating smaller scale compartmental structures, ranging from 0.1 to $0.5 \mu \mathrm{m}$, on titanium than is typically seen on acid-etched micro-rough titanium. The formation of compartments was even and uniform under the controlled temperature. Given the unique biological effects demonstrated in this study, this surface may be useful when an increased osteoconductivity but not a strong anchorage in bone is desired, such as in 
temporal bone regeneration devices. For instance, titanium mesh plates, pins, and screws are used for scaffolding and guiding new bone formation and fixing bone pieces, with the intention of removal after the purpose has been accomplished. Because of the considerable increase in the osteoconductivity of this sub-micro-rough surface, bone healing around the device would be promoted. In contrast, the minimal increase in bone-titanium integration ability would facilitate relatively easy removal of the device.

We examined the cell attachment, proliferation, and functional phenotypes of osteoblast-like rat bone marrow in this study. The rat bone marrow cells used in this experiment are known to differentiate towards an osteoblast-like phenotype when supplemented with dexamethasone and $\beta$-glycerophosphate [21-24]. In addition, many studies related to osteoblasts have been reported using various cells, such as bone-marrow-derived mesenchymal stem cells, MC3T3-E1, and MG-63 [25-31]. Osteoblast differentiation methods have been reported to use many kinds of reagents, including 1,25-dihydroxyvitamin $\mathrm{D}_{3}$ [32], hormones [33,34], growth factors [35,36], bone morphogenetic proteins [37,38], aluminum chloride $\left(\mathrm{AlCl}_{3}\right)$ [39], sodium fluoride $(\mathrm{NaF})$ [35], prostaglandins [40,41], $\beta$-glycerophosphate [30], and ascorbic acid [31]. There are also many reports on the timing of administering differentiation-inducing reagents to these cells $[27,42,43]$. Cells harvested from rat bone marrow were differentiated in this study using an osteogenic induction medium containing ascorbic acid, $\beta$-glycerophosphate, and dexamethasone. Since titanium materials do not have osteogenic induction capability in the material itself, it was necessary to differentiate and induce cells before seeding in order to examine osteoconduction on each type of titanium surface in the present study. In past studies, we have reported many changes in the differentiation, proliferation, and genetic phenotype of mature osteoblast cells before seeding cells using the osteogenic induction medium [44-47]. It is necessary to use various osteogenic induction reagents, change the timing of the addition of the osteogenic induction medium, and conduct experiments in a comprehensive manner in future studies. Moreover, since cells harvested from bone marrow cells did not use cell-sorting in this study, we should also conduct detailed studies on sub-micro-rough surfaces using rat and human mesenchymal stem cells.

Another important advantage provided by this sub-micro-rough surface is the amelioration of the adverse effects of micro-rough titanium. Micro-rough titanium surfaces are known to decrease the number of cells that attach during the initial stage of cell culture as well as the rate of cell proliferation $[45,48]$. This was observed in the present study, consistent with previous reports. The sub-micro-rough surface increased the number of attached cells and the cell density more than 2-fold compared with those of the micro-rough titanium. In particular, the number of attached cells on the sub-micro-rough surface was equivalent to that on the machined surface. The amount of bone formed is dependent on the number of osteoblasts present at the titanium surface. This new biological effect of the sub-micro-rough surface is meaningful from this perspective.

Another important finding from the present in vitro study is that the sub-micro-rough surface challenges a known principle of osteoblasts, i.e., the inverted relationship between proliferation and differentiation. For instance, the rate of proliferation is reduced on rougher biomaterial surfaces, although rougher surfaces have an advantage in that they promote cellular differentiation $[45,49]$. Similarly, micro-roughened titanium surfaces promote osteoblastic differentiation better than machined, smooth surfaces and result in faster bone formation. However, bone volume is ultimately reduced compared to that achieved with a machined surface owing to the reduction in osteoblastic proliferation. Consistent with this, several in vitro studies have shown that cell density and proliferative activity are reduced on micro-rough titanium surfaces compared with those on relatively smoother surfaces [50,51]. Given this, we anticipated that the sub-micro-rough surface would show a higher cell density than the micro-rough surface, which turned out to be true. However, the sub-micro-rough surface also showed accelerated osteoblastic differentiation, as demonstrated by the upregulated expression of osteoblastic genes. This was supported by the increased deposition of calcium on the sub-micro-rough surface. However, since we are using an osteogenic induction medium in these experiments, it is possible that osteoblasts are somewhat emphasized in differentiation rather than proliferation. Since titanium 
materials do not have osteoinduction capabilities, the cells require an osteogenic induction medium. Therefore, we need to further investigate the effects of the surfaces by creating a concentration gradient in the osteogenic induction medium and reducing the reagents contained in it.

We conducted an in vivo push-in test to evaluate the ability of implants to integrate with bone. Bone-implant integration was the strongest for the micro-rough surface, and there was no significant increase from the use of a sub-micro-rough surface. Given the strong promotion of osteoblastic differentiation and elevation of calcium deposition on the sub-micro-rough surface, we hypothesize that the surface pits of the low-temperature acid-etched titanium, which were 0.1 to $0.5 \mu \mathrm{m}$ in width and $0.1 \mu \mathrm{m}$ in depth, were not large or deep enough for the extracellular matrix to effectively engage.

In the present study, we did not histologically evaluate the bone-implant interface of the three kinds of implant after the push-in test. We placed acid-etched implants and machined implants in a rat femur model in a previous study and examined their bone histological imaging around implants with Goldner's trichrome stain [45]. From these results, the bone-implant contact was significantly higher on the acid-etched surface than on the machined surface. Furthermore, we also reported the surface of the acid-etched implant and machined implant after push-in tests with implant surface morphology based on SEM and elemental composition analysis of the implant surface using energy dispersive X-ray spectroscopy (EDS) [52]. The machined implant after a push-in test at 4 weeks showed exposure without notable bone-like structures, with the accompanying EDS spectrum representing clear and high peaks of titanium and lower peaks of phosphorous and calcium. On the other hand, acid-etched implants showed the robust formation of bone-like structures, which were represented on the EDS spectrum by clear peaks of calcium and phosphorus. Moreover, the sub-micro-rough surface may have a bone-implant contact equivalent to that of the machined surface because there was no significant difference between them in terms of push-in value after 2 weeks of implantation. Considering the above, it may be predicted that many bone-like structures are detached from the implant interface on the sub-micro-rough surface, as on the machined surface. Therefore, we will need to conduct morphological and histological evaluations on the sub-micro-rough surface between implants and bone tissue after push-in tests using histological analysis and SEM in future studies. We should also evaluate the elemental composition of the sub-micro-rough implant surface using EDS.

This study revealed for the first time a disproportionate effect of titanium surface roughness on osteoblastic differentiation and bone integration capability through the introduction of a newly developed sub-micro-rough surface. This sub-micro-rough titanium is unique in terms of promoting osteoblastic differentiation while increasing proliferation. The present study also provides a new strategy for designing titanium surfaces with better osteoconductivity and minimal interlocking to bone tissue.

\section{Materials and Methods}

\subsection{Titanium Sample Preparation}

Disks (20 mm in diameter and $1 \mathrm{~mm}$ in thickness) and cylindrical implants (1 $\mathrm{mm}$ in diameter, $2 \mathrm{~mm}$ in length) of grade 2 commercially pure titanium were prepared with a machined surface (Figure $1 \mathrm{a}, \mathrm{d}$ ), a micro-rough surface introduced by regular acid-etching with $67 \%(w / w) \mathrm{H}_{2} \mathrm{SO}_{4}$ (Sigma-Aldrich, St. Louis, MO, USA) at $120^{\circ} \mathrm{C}$ for $75 \mathrm{~s}$ (Figure $1 \mathrm{~b}, \mathrm{e}$ ), or a sub-micro-rough surface introduced by low-temperature acid-etching with $67 \% \mathrm{H}_{2} \mathrm{SO}_{4}$ at $95^{\circ} \mathrm{C}$ for $75 \mathrm{~s}$ (Figure $\left.1 \mathrm{c}, \mathrm{f}\right)$. These were placed in a sealed container and stored in a dark room (temperature, $23^{\circ} \mathrm{C}$; humidity, $60 \%$ ) for 4 weeks.

\subsection{Titanium Surface Characterization}

The surface morphologies of the machined, micro-rough, and sub-micro-rough surfaces were examined by SEM (Nova 230 Nano SEM, FEI, Hillsboro, OR, USA). The surface roughness was quantified by measuring average roughness $(R a)$, mean peak-to-valley height $(R z)$, average width of 
roughness profile elements (Rsm), and skewness of roughness profile (Rsk) values using a 3-dimensional profiler (Mex, Alicona Imaging GmbH, Raaba, Graz, Austria).

\subsection{Osteoblastic Cell Culture}

Bone marrow-derived osteoblastic cells were isolated from the femurs of 8-week-old male Sprague-Dawley rats and placed into alpha-modified Eagle's medium supplemented with $15 \%$ fetal bovine serum, $50 \mathrm{mg} / \mathrm{mL}$ ascorbic acid, $10 \mathrm{mM}$ Na- $\beta$-glycerophosphate, $10^{-8} \mathrm{M}$ dexamethasone, and antibiotic-antimycotic solution containing 10,000 units/mL penicillin G sodium, 10,000 mg/mL streptomycin sulfate, and $25 \mathrm{mg} / \mathrm{mL}$ amphotericin $\mathrm{B}$, as previously described [53]. Cells were incubated in a humidified atmosphere of $95 \%$ air and $5 \% \mathrm{CO}_{2}$ at $37^{\circ} \mathrm{C}$. At $80 \%$ confluency, cells were detached using $0.25 \%$ trypsin- 1 mM EDTA- $4 \mathrm{Na}$ and seeded onto titanium disks placed in a 12-well culture dish at a density of $3 \times 10^{4}$ cells $/ \mathrm{cm}^{2}$. The culture medium was renewed every 3 days.

\subsection{Cell Attachment and Density Assay}

Initial attachment of cells was evaluated by measuring the number of cells attached to titanium disks after $24 \mathrm{~h}$ of incubation. Propagated cells were also quantified as cell density on day 3 of culture. These quantifications were performed using a WST-1-based colorimetric assay (WST-1, Roche Applied Science, Mannheim, Germany). A culture well was incubated at $37^{\circ} \mathrm{C}$ for $1 \mathrm{~h}$ with $100 \mu \mathrm{L}$ of WST-1 reagent. The amount of formazan product was measured using a multi-detection microplate reader (Synergy ${ }^{\mathrm{TM}}$ HT; BioTek Instruments, Inc., Winooski, VT, USA) at a wavelength of $450 \mathrm{~nm}$.

\subsection{Gene Expression Analysis}

Total RNA was extracted from cultures on days 7 and 14 using the TRIzol reagent (Life Technologies, Carlsbad, CA, USA) and purified using Direct-zol ${ }^{\mathrm{TM}}$ RNA MiniPrep (ZYMO RESEARCH Co., Irvine, CA, USA) according to the manufacturer's protocol when the cells had reached $70 \%$ confluence. The total amount of RNA and its purity were determined using a NanoDrop ${ }^{\mathrm{TM}}$ One (Thermo Fisher Scientific, Waltham, MA, USA) spectrophotometer. RNA with A260/A280 ratios between 1.8 and 2.0 were considered to be of high purity. Purified RNA was stored at $-80^{\circ} \mathrm{C}$. Purified RNA was treated with the DNase I reagent (Invitrogen, Carlsbad, CA, USA) and converted into complementary DNA (cDNA) using a SuperScript ${ }^{\circledR}$ VILO ${ }^{\mathrm{TM}}$ cDNA System Kit (Invitrogen) as outlined by the manufacturer. Total RNA $(1 \mu \mathrm{g})$ was used, and reverse transcription was performed in a final volume of $20 \mu \mathrm{L}$, following the manufacturer's instructions. cDNA samples were stored at $-20^{\circ} \mathrm{C}$ for later use. Real-time PCR was conducted with the QuantStudio ${ }^{\mathrm{TM}} 3$ Real-Time PCR System (Applied Biosystems, Waltham, MA, USA) using TaqMan ${ }^{\circledR}$ universal master mix II (Applied Biosystems). Relative gene expression of the following genes was quantified: Col1a1 (Assay ID: Rn01463848_m1, Applied Biosystems) and Opn (Assay ID: Rn0068103_m1, Applied Biosystems). Glyceraldehyde-3-phosphate dehydrogenase (Gapdh) (Assay ID: Rn01775763_g1, Applied Biosystems) was used as a "housekeeping" gene for normalizing mRNA levels. Quantification of each gene was performed in triplicate, using 96-well plates and the cDNA obtained as described previously [54]. TaqMan gene expression assays specific to each gene were performed under conditions recommended by the manufacturer. Analysis of relative gene expression was performed with the $2^{-\Delta \Delta \mathrm{Ct}}$ method [55]. Thermocycling conditions were as follows: $95^{\circ} \mathrm{C}$ for $10 \mathrm{~min}$, followed by 50 cycles at $95^{\circ} \mathrm{C}$ for $15 \mathrm{~s}$ and $60^{\circ} \mathrm{C}$ for $60 \mathrm{~s}$. The expression levels of various genes were expressed as fold differences in gene expression relative to that of the machined surface.

\subsection{Mineralization Assay}

The mineralization capabilities of cultures were evaluated on day 14 by colorimetry-based assays. The cultures were washed with $\mathrm{ddH}_{2} \mathrm{O}$ and incubated overnight in $1 \mathrm{~mL}$ of $0.5 \mathrm{M} \mathrm{HCl}$ solution (Sigma-Aldrich) with gentle shaking. The solution was mixed with $o$-cresolphthalein complexone in an alkaline medium (Stanbio LiquidColor, Stanbio, Boerne, TX, USA) to produce a purple calcium-cresolphthalein complexone complex. Color intensity was measured by a multi-detection 
microplate reader (Synergy ${ }^{\mathrm{TM}}$ HT, BioTek Instruments, Inc.) at $550 \mathrm{~nm}$ wavelength. The mineralization capability of each titanium disk was also confirmed by visualizing mineralized nodule areas via Alizarin red staining. On day 14 of culture, the specimens were washed twice with $1 \times \mathrm{PBS}$ at $37^{\circ} \mathrm{C}$ and stained for $5 \mathrm{~min}$ using $1 \%$ Alizarin red ( $\mathrm{pH}$ 6.3-6.4). The titanium disks were then rinsed twice with $\mathrm{ddH}_{2} \mathrm{O}$ and air-dried.

\subsection{Cell Detachment Assay}

The ability of titanium surfaces to retain cells was evaluated by a chemical detachment assay. At culture days 3, 7, and 14, cells were gently rinsed twice with PBS and treated with $300 \mu \mathrm{L}$ of $0.05 \%$ trypsin- $1 \mathrm{mmol} / \mathrm{L}$ EDTA- $4 \mathrm{Na}$ for $1 \mathrm{~min}$ at $37^{\circ} \mathrm{C}$. A hematocytometer was used to count the number of detached cells. Then, the remaining cells on the surfaces were completely detached using $300 \mu \mathrm{L}$ of $0.25 \%$ trypsin- $1 \mathrm{mmol} / \mathrm{L}$ EDTA- $4 \mathrm{Na}$ for $5 \mathrm{~min}$ at $37^{\circ} \mathrm{C}$ and counted. SEM of the selected cultures was used to confirm the absence of any remaining cells after the second detachment. The percentage of detached cells was calculated according to the following equation: ((Number of detached cells)/(Number of detached cells + Number of remaining cells) $) \times 100(\%)$ [18]. Three independent cultures were analyzed for each group, and the data were averaged.

\subsection{Implant Surgery}

Ten-week-old male Sprague-Dawley rats were anesthetized by inhalation of $1 \%-2 \%$ isoflurane. Only left femurs were used to receive an implant. The left leg area was shaved and scrubbed with $10 \%$ povidone-iodine solution. The distal aspects of the left femurs were carefully exposed through skin incision and muscle dissection. The flat surface closest to the distal end was selected for implant placement. A $1 \mathrm{~mm}$ diameter $\times 2 \mathrm{~mm}$ length implant site was prepared $10 \mathrm{~mm}$ from the distal edge of the femur by drilling with a $0.8 \mathrm{~mm}$ round burr and was enlarged using reamers (\#ISO 090 and 100) as described previously $[44,53,56]$. For cooling and cleaning, the site was profusely irrigated with a sterile isotonic saline solution. One cylindrical machined, micro-rough, or sub-micro-rough titanium implant was inserted into each prepared hole per femur. Surgical sites were then closed in layers. Muscle and skin were sutured separately with resorbable suture thread. The total number of animals used was 15, distributed among the machined, micro-rough, and sub-micro-rough implant groups. All experiments were performed following a protocol approved by The Chancellor's Animal Research Committee at the University of California at Los Angeles (ARC \#2005-175-41E, approved on 30 January 2018) and followed the PHS Policy for the Humane Care and Use of Laboratory Animals and the UCLA Animal Care and Use Training Manual guidelines.

\subsection{Biomechanical Implant Push-In Test}

The biomechanical implant push-in test was conducted to assess the biomechanical strength of bone-implant integration. The procedure details and method validation are described elsewhere $[57,58]$. Femurs containing the cylindrical implant were harvested after 2 weeks of healing and embedded into an auto-polymerizing resin with the top surface of the implant horizontal. A testing machine (Instron 5544 electromechanical testing system; Instron, Norwood, MA, USA) equipped with a 2000-N load cell and a pushing rod (diameter, $0.8 \mathrm{~mm}$ ) was used to load the implant vertically downward at a crosshead speed of $1 \mathrm{~mm} / \mathrm{min}$. The push-in value was determined by measuring the peak of the load-displacement curve.

\subsection{Statistical Analysis}

Data on surface roughness parameters were collected from six sites on three different disks $(n$ $=6)$. All culture studies were performed in triplicate $(n=3)$. Fifteen animals were used for the biomechanical push-in test $(n=5)$. Statistical analyses were carried out using the SPSS (Version 22.0; SPSS Inc., Chicago, IL, USA) statistics program. All statistical analyses were conducted using one-way analysis of variance (ANOVA) followed by a Tukey's post-test to assess differences among groups. All 
data are expressed as the group mean \pm standard deviation. Results with a probability level of 0.05 or less were considered significant.

\section{Conclusions}

Osteoblastic differentiation was promoted on a newly introduced sub-micro-rough titanium. The effect was even greater than that on micro-rough titanium. The number of attached cells and the cell density were also greater on the sub-micro-rough surface than on the micro-rough surface. However, the sub-micro-rough surface's in vivo bone integration capability was markedly weaker than that of the micro-rough surface. Thus, the present study reveals disproportionate effects of titanium surface roughness on osteoblastic differentiation and bone integration capability. A new strategy for designing titanium surfaces with better osteoconductivity and minimal interlocking to bone is provided.

Author Contributions: J.S. performed experiments, data analysis, and manuscript writing; N.S. designed and performed experiments, data analysis, and interpretation; M.I. was involved in experimental design and performed experiments and data analysis; T.O. (Takahisa Okubo) and M.H. performed experiments; T.O. (Takahiro Ogawa) was involved in experimental deign, data analysis and interpretation, and manuscript writing; and all authors discussed the results and commented on the manuscript, as well as approved the final version of the manuscript.

Funding: This research received no external funding.

Acknowledgments: We would like to thank Editage (www.editage.com) for English language editing.

Conflicts of Interest: The authors declare no conflict of interest.

\section{Abbreviations}

ANOVA One-way analysis of variance

cDNA Complementary DNA

Col1a1 Collagen type I alpha 1 chain

ECM Extracellular matrix

Gapdh Glyceraldehyde-3-phosphate dehydrogenase

Opn Osteopontin

PCR Polymerase chain reaction

SEM Scanning electron microscopy

WST Water soluble tetrazolium salts

\section{References}

1. Jemat, A.; Ghazali, M.J.; Razali, M.; Otsuka, Y. Surface Modifications and Their Effects on Titanium Dental Implants. Biomed. Res. Int. 2015, 2015, 791725. [CrossRef] [PubMed]

2. Koh, J.; Berger, A.; Benhaim, P. An Overview of Internal Fixation Implant Metallurgy and Galvanic Corrosion Effects. J. Hand. Surg. Am. 2015, 40, 1703-1710. [CrossRef] [PubMed]

3. Jimbo, R.; Albrektsson, T. Long-term clinical success of minimally and moderately rough oral implants: A review of 71 studies with 5 years or more of follow-up. Implant Dent. 2015, 24, 62-69. [CrossRef] [PubMed]

4. Leno, M.B.; Liu, S.Y.; Chen, C.T.; Liao, H.T. Comparison of functional outcomes and patient-reported satisfaction between titanium and absorbable plates and screws for fixation of mandibular fractures: A one-year prospective study. J. Craniomaxillofac. Surg. 2017, 45, 704-709. [CrossRef] [PubMed]

5. Rengaraja, D.; Jagade, M.; Rao, K.; Sonate, R.; Singhal, A. Reconstruction of Maxilla with Titanium Mesh and Fascia Lata - A Case Report. J. Clin. Diagn. Res. 2017, 11, MD03-MD05. [CrossRef] [PubMed]

6. Banakis Hartl, R.M.; Mattingly, J.K.; Greene, N.T.; Jenkins, H.A.; Cass, S.P.; Tollin, D.J. A Preliminary Investigation of the Air-Bone Gap: Changes in Intracochlear Sound Pressure With Air- and Bone-conducted Stimuli After Cochlear Implantation. Otol. Neurotol. 2016, 37, 1291-1299. [CrossRef] [PubMed]

7. Ait Moussa, A.; Yadav, R. Optimization of a Functionally Graded Material Stem in the Femoral Component of a Cemented Hip Arthroplasty: Influence of Dimensionality of FGM. J. Med. Eng. 2017, 2017, 3069351. [CrossRef] 
8. Tabuchi, M.; Ikeda, T.; Hirota, M.; Nakagawa, K.; Park, W.; Miyazawa, K.; Goto, S.; Ogawa, T. Effect of UV Photofunctionalization on Biologic and Anchoring Capability of Orthodontic Miniscrews. Int. J. Oral Maxillofac. Implants 2015, 30, 868-879. [CrossRef]

9. Kaluderovic, M.R.; Schreckenbach, J.P.; Graf, H.L. Titanium dental implant surfaces obtained by anodic spark deposition - From the past to the future. Mater. Sci. Eng. C Mater. Biol. Appl. 2016, 69, 1429-1441. [CrossRef]

10. Meng, H.W.; Chien, E.Y.; Chien, H.H. Dental implant bioactive surface modifications and their effects on osseointegration: A review. Biomark Res. 2016, 4, 24. [CrossRef]

11. Gittens, R.A.; Olivares-Navarrete, R.; Schwartz, Z.; Boyan, B.D. Implant osseointegration and the role of microroughness and nanostructures: Lessons for spine implants. Acta Biomater. 2014, 10, 3363-3371. [CrossRef] [PubMed]

12. Boyan, B.D.; Lotz, E.M.; Schwartz, Z. $\left(^{*}\right)$ Roughness and Hydrophilicity as Osteogenic Biomimetic Surface Properties. Tissue Eng. Part A 2017, 23, 1479-1489. [CrossRef] [PubMed]

13. Lai, M.; Hermann, C.D.; Cheng, A.; Olivares-Navarrete, R.; Gittens, R.A.; Bird, M.M.; Walker, M.; Cai, Y.; Cai, K.; Sandhage, K.H.; et al. Role of alpha2beta1 integrins in mediating cell shape on microtextured titanium surfaces. J. Biomed. Mater. Res. A 2015, 103, 564-573. [CrossRef] [PubMed]

14. Boyan, B.D.; Cheng, A.; Olivares-Navarrete, R.; Schwartz, Z. Implant Surface Design Regulates Mesenchymal Stem Cell Differentiation and Maturation. Adv. Dent. Res. 2016, 28, 10-17. [CrossRef] [PubMed]

15. Olivares-Navarrete, R.; Hyzy, S.L.; Hutton, D.L.; Erdman, C.P.; Wieland, M.; Boyan, B.D.; Schwartz, Z. Direct and indirect effects of microstructured titanium substrates on the induction of mesenchymal stem cell differentiation towards the osteoblast lineage. Biomaterials 2010, 31, 2728-2735. [CrossRef] [PubMed]

16. Bosshardt, D.D.; Chappuis, V.; Buser, D. Osseointegration of titanium, titanium alloy and zirconia dental implants: Current knowledge and open questions. Periodontol. 2000 2017, 73, 22-40. [CrossRef] [PubMed]

17. Boyan, B.D.; Lossdorfer, S.; Wang, L.; Zhao, G.; Lohmann, C.H.; Cochran, D.L.; Schwartz, Z. Osteoblasts generate an osteogenic microenvironment when grown on surfaces with rough microtopographies. Eur. Cell Mater. 2003, 6, 22-27. [CrossRef]

18. Att, W.; Yamada, M.; Ogawa, T. Effect of titanium surface characteristics on the behavior and function of oral fibroblasts. Int. J. Oral Maxillofac. Implants 2009, 24, 419-431.

19. Iwaya, Y.; Machigashira, M.; Kanbara, K.; Miyamoto, M.; Noguchi, K.; Izumi, Y.; Ban, S. Surface properties and biocompatibility of acid-etched titanium. Dent. Mater. J. 2008, 27, 415-421. [CrossRef]

20. Le Guehennec, L.; Soueidan, A.; Layrolle, P.; Amouriq, Y. Surface treatments of titanium dental implants for rapid osseointegration. Dent. Mater. 2007, 23, 844-854. [CrossRef]

21. Maniatopoulos, C.; Sodek, J.; Melcher, A.H. Bone formation in vitro by stromal cells obtained from bone marrow of young adult rats. Cell Tissue Res. 1988, 254, 317-330. [CrossRef]

22. Matsuzaka, K.; Walboomers, X.F.; de Ruijter, J.E.; Jansen, J.A. The effect of poly-L-lactic acid with parallel surface micro groove on osteoblast-like cells in vitro. Biomaterials 1999, 20, 1293-1301. [CrossRef]

23. ter Brugge, P.J.; Wolke, J.G.; Jansen, J.A. Effect of calcium phosphate coating crystallinity and implant surface roughness on differentiation of rat bone marrow cells. J. Biomed. Mater. Res. 2002, 60, 70-78. [CrossRef]

24. van den Dolder, J.; Vehof, J.W.; Spauwen, P.H.; Jansen, J.A. Bone formation by rat bone marrow cells cultured on titanium fiber mesh: Effect of in vitro culture time. J. Biomed. Mater. Res. 2002, 62, 350-358. [CrossRef]

25. Dalby, M.J.; Gadegaard, N.; Tare, R.; Andar, A.; Riehle, M.O.; Herzyk, P.; Wilkinson, C.D.; Oreffo, R.O. The control of human mesenchymal cell differentiation using nanoscale symmetry and disorder. Nat. Mater. 2007, 6, 997-1003. [CrossRef]

26. Li, P.; Kong, J.; Chen, Z.; Huang, S.; Lv, G.; Wei, B.; Wei, J.; Jing, K.; Quan, J.; Chu, J. Aloin promotes osteogenesis of bone-marrow-derived mesenchymal stem cells via the ERK1/2-dependent Runx2 signaling pathway. J. Nat. Med. 2019, 73, 104-113. [CrossRef]

27. Li, X.; Huang, Y.; Zheng, L.; Liu, H.; Niu, X.; Huang, J.; Zhao, F.; Fan, Y. Effect of substrate stiffness on the functions of rat bone marrow and adipose tissue derived mesenchymal stem cells in vitro. J. Biomed. Mater. Res. A 2014, 102, 1092-1101. [CrossRef]

28. Morinaga, K.; Sasaki, H.; Park, S.; Hokugo, A.; Okawa, H.; Tahara, Y.; Colwell, C.S.; Nishimura, I. Neuronal PAS domain 2 (Npas2) facilitated osseointegration of titanium implant with rough surface through a neuroskeletal mechanism. Biomaterials 2019, 192, 62-74. [CrossRef] 
29. Guo, J.; Padilla, R.J.; Ambrose, W.; De Kok, I.J.; Cooper, L.F. The effect of hydrofluoric acid treatment of TiO2 grit blasted titanium implants on adherent osteoblast gene expression in vitro and in vivo. Biomaterials 2007, 28, 5418-5425. [CrossRef]

30. Chou, Y.F.; Huang, W.; Dunn, J.C.; Miller, T.A.; Wu, B.M. The effect of biomimetic apatite structure on osteoblast viability, proliferation, and gene expression. Biomaterials 2005, 26, 285-295. [CrossRef]

31. Schwartz, Z.; Olivares-Navarrete, R.; Wieland, M.; Cochran, D.L.; Boyan, B.D. Mechanisms regulating increased production of osteoprotegerin by osteoblasts cultured on microstructured titanium surfaces. Biomaterials 2009, 30, 3390-3396. [CrossRef]

32. Kurose, H.; Yamaoka, K.; Okada, S.; Nakajima, S.; Seino, Y. 1,25-Dihydroxyvitamin D3 [1,25-(OH)2D3] increases insulin-like growth factor I (IGF-I) receptors in clonal osteoblastic cells. Study on interaction of IGF-I and 1,25-(OH)2D3. Endocrinology 1990, 126, 2088-2094. [CrossRef]

33. Ernst, M.; Rodan, G.A. Increased activity of insulin-like growth factor (IGF) in osteoblastic cells in the presence of growth hormone (GH): Positive correlation with the presence of the GH-induced IGF-binding protein BP-3. Endocrinology 1990, 127, 807-814. [CrossRef]

34. Masuyama, A.; Ouchi, Y.; Sato, F.; Hosoi, T.; Nakamura, T.; Orimo, H. Characteristics of steroid hormone receptors in cultured MC3T3-E1 osteoblastic cells and effect of steroid hormones on cell proliferation. Calcif. Tissue Int. 1992, 51, 376-381. [CrossRef]

35. Siddhanti, S.R.; Quarles, L.D. Molecular to pharmacologic control of osteoblast proliferation and differentiation. J. Cell Biochem. 1994, 55, 310-320. [CrossRef]

36. Yada, M.; Yamaguchi, K.; Tsuji, T. NGF stimulates differentiation of osteoblastic MC3T3-E1 cells. Biochem. Biophys. Res Commun 1994, 205, 1187-1193. [CrossRef]

37. Vukicevic, S.; Luyten, F.P.; Reddi, A.H. Osteogenin inhibits proliferation and stimulates differentiation in mouse osteoblast-like cells (MC3T3-E1). Biochem. Biophys. Res. Commun. 1990, 166, 750-756. [CrossRef]

38. Takuwa, Y.; Ohse, C.; Wang, E.A.; Wozney, J.M.; Yamashita, K. Bone morphogenetic protein-2 stimulates alkaline phosphatase activity and collagen synthesis in cultured osteoblastic cells, MC3T3-E1. Biochem. Biophys. Res. Commun. 1991, 174, 96-101. [CrossRef]

39. Quarles, L.D.; Wenstrup, R.J.; Castillo, S.A.; Drezner, M.K. Aluminum-induced mitogenesis in MC3T3-E1 osteoblasts: Potential mechanism underlying neoosteogenesis. Endocrinology 1991, 128, 3144-3151. [CrossRef]

40. Raisz, L.G.; Alander, C.B.; Fall, P.M.; Simmons, H.A. Effects of prostaglandin F2 alpha on bone formation and resorption in cultured neonatal mouse calvariae: Role of prostaglandin E2 production. Endocrinology 1990, 126, 1076-1079. [CrossRef]

41. Koshihara, Y.; Kawamura, M. Prostaglandin D2 stimulates calcification of human osteoblastic cells. Biochem. Biophys. Res. Commun. 1989, 159, 1206-1212. [CrossRef]

42. Saruwatari, L.; Aita, H.; Butz, F.; Nakamura, H.K.; Ouyang, J.; Yang, Y.; Chiou, W.A.; Ogawa, T. Osteoblasts generate harder, stiffer, and more delamination-resistant mineralized tissue on titanium than on polystyrene, associated with distinct tissue micro- and ultrastructure. J. Bone Miner. Res. 2005, 20, 2002-2016. [CrossRef]

43. Deligianni, D.D.; Katsala, N.; Ladas, S.; Sotiropoulou, D.; Amedee, J.; Missirlis, Y.F. Effect of surface roughness of the titanium alloy $\mathrm{Ti}-6 \mathrm{Al}-4 \mathrm{~V}$ on human bone marrow cell response and on protein adsorption. Biomaterials 2001, 22, 1241-1251. [CrossRef]

44. Rezaei, N.M.; Hasegawa, M.; Ishijima, M.; Nakhaei, K.; Okubo, T.; Taniyama, T.; Ghassemi, A.; Tahsili, T.; Park, W.; Hirota, M.; et al. Biological and osseointegration capabilities of hierarchically (meso-/micro-/nano-scale) roughened zirconia. Int. J. Nanomedicine 2018, 13, 3381-3395. [CrossRef]

45. Aita, H.; Hori, N.; Takeuchi, M.; Suzuki, T.; Yamada, M.; Anpo, M.; Ogawa, T. The effect of ultraviolet functionalization of titanium on integration with bone. Biomaterials 2009, 30, 1015-1025. [CrossRef]

46. Att, W.; Takeuchi, M.; Suzuki, T.; Kubo, K.; Anpo, M.; Ogawa, T. Enhanced osteoblast function on ultraviolet light-treated zirconia. Biomaterials 2009, 30, 1273-1280. [CrossRef]

47. Kubo, K.; Tsukimura, N.; Iwasa, F.; Ueno, T.; Saruwatari, L.; Aita, H.; Chiou, W.A.; Ogawa, T. Cellular behavior on $\mathrm{TiO} 2$ nanonodular structures in a micro-to-nanoscale hierarchy model. Biomaterials 2009, 30, 5319-5329. [CrossRef]

48. Takeuchi, K.; Saruwatari, L.; Nakamura, H.K.; Yang, J.M.; Ogawa, T. Enhanced intrinsic biomechanical properties of osteoblastic mineralized tissue on roughened titanium surface. J. Biomed. Mater. Res. A 2005, 72, 296-305. [CrossRef] 
49. Hori, N.; Iwasa, F.; Ueno, T.; Takeuchi, K.; Tsukimura, N.; Yamada, M.; Hattori, M.; Yamamoto, A.; Ogawa, T. Selective cell affinity of biomimetic micro-nano-hybrid structured $\mathrm{TiO} 2$ overcomes the biological dilemma of osteoblasts. Dent. Mater. 2010, 26, 275-287. [CrossRef]

50. Tsukimura, N.; Kojima, N.; Kubo, K.; Att, W.; Takeuchi, K.; Kameyama, Y.; Maeda, H.; Ogawa, T. The effect of superficial chemistry of titanium on osteoblastic function. J. Biomed. Mater. Res. A 2008, 84, 108-116. [CrossRef]

51. Sato, N.; Kubo, K.; Yamada, M.; Hori, N.; Suzuki, T.; Maeda, H.; Ogawa, T. Osteoblast mechanoresponses on Ti with different surface topographies. J. Dent. Res. 2009, 88, 812-816. [CrossRef]

52. Ogawa, T.; Ozawa, S.; Shih, J.H.; Ryu, K.H.; Sukotjo, C.; Yang, J.M.; Nishimura, I. Biomechanical evaluation of osseous implants having different surface topographies in rats. J. Dent. Res. 2000, 79, 1857-1863. [CrossRef]

53. Ikeda, T.; Hagiwara, Y.; Hirota, M.; Tabuchi, M.; Yamada, M.; Sugita, Y.; Ogawa, T. Effect of photofunctionalization on fluoride-treated nanofeatured titanium. J. Biomater. Appl. 2014, 28, 1200-1212. [CrossRef]

54. Saruta, J.; To, M.; Sugimoto, M.; Yamamoto, Y.; Shimizu, T.; Nakagawa, Y.; Inoue, H.; Saito, I.; Tsukinoki, K. Salivary Gland Derived BDNF Overexpression in Mice Exerts an Anxiolytic Effect. Int. J. Mol. Sci. 2017, 18, 1902. [CrossRef]

55. Takayama, T.; Dai, J.; Tachi, K.; Shohara, R.; Kasai, H.; Imamura, K.; Yamano, S. The potential of stromal cell-derived factor-1 delivery using a collagen membrane for bone regeneration. J. Biomater. Appl. 2017, 31, 1049-1061. [CrossRef]

56. Park, W.; Ishijima, M.; Hirota, M.; Soltanzadeh, P.; Ogawa, T. Engineering bone-implant integration with photofunctionalized titanium microfibers. J. Biomater. Appl. 2016, 30, 1242-1250. [CrossRef]

57. Ishijima, M.; Ghassemi, A.; Soltanzadeh, P.; Tanaka, M.; Nakhaei, K.; Park, W.; Hirota, M.; Tsukimura, N.; Ogawa, T. Effect of UV Photofunctionalization on Osseointegration in Aged Rats. Implant Dent. 2016, 25, 744-750. [CrossRef]

58. Soltanzadeh, P.; Ghassemi, A.; Ishijima, M.; Tanaka, M.; Park, W.; Iwasaki, C.; Hirota, M.; Ogawa, T. Success rate and strength of osseointegration of immediately loaded UV-photofunctionalized implants in a rat model. J. Prosthet. Dent. 2017, 118, 357-362. [CrossRef] 